\title{
LA VÍCTIMA Y SU RESARCIMIENTO EN LOS SISTEMAS PENALES COLOMBIANOS*
}

DOI: http://dx.doi.org/10.17981/juridcuc.11.1.2015.2

Recibido: 19 de Febrero de 2015 / Revisado: 09 de Abril de 2015 / Aceptado: 29 de Mayo de 2015

\author{
Laura Andrea Acosta Zárate** - Ricardo Hernán Medina Rico*** \\ Universidad del Rosario - Bogotá
}

Puede citar el presente artículo así: / To reference this article:

Acosta, L. \& Medina, R. (2015). La Víctima y su Resarcimiento en los Sistemas Penales Colombianos. Jurídicas CUC, 11(1), 39-58. doi: http://dx.doi.org/10.17981/juridcuc.11.1.2015.2

\section{Resumen}

El presente artículo examina las figuras del incidente de reparación integral y la demanda de parte civil como mecanismos de acceso al resarcimiento de una víctima dentro del proceso penal, ya sea en la Ley 906 de 2004 o en la aún vigente Ley 600 de 2000. También es un estudio de las diferencias y similitudes entre ambas instituciones.

\section{Palabras clave:}

Daño, proceso penal, reparación, responsabilidad penal, víctimas.

\footnotetext{
" El artículo es resultado de una investigación desarrollada en la línea de "Problemas actuales del Derecho Penal" del Grupo deiInvestigación en Derecho Penal de la Universidad del Rosario.

** Abogada de la Universidad del Rosario con profundización en Derecho Penal de la misma universidad. Estudiante de la especialización en Ciencias Penales y Criminológicas de la Universidad Externado de Colombia. Profesora universitaria y conferencista invitada. Abogada litigante y consultora. Correo electrónico: acostaz.laura@urosario.edu.co

****A Abogado litigante y consultor en Derecho Penal y Disciplinario de la Universidad del Rosario. Especialista en Derecho Penal y en Derecho Administrativo de la Universidad del Rosario y especialista en Derecho Penal de la Universidad de Salamanca (España). Estudiante del Máster Universitario en Justicia Criminal de la Universidad Carlos III de Madrid (España). Joven investigador en Derecho Penal de la Facultad de Jurisprudencia de la Universidad del Rosario. Profesor universitario. Correo electrónico: ricardo.medina@urosario.edu.co
} 


\section{VICTIMS AND COMPENSATORY MECHANISMS IN THE COLOMBIAN CRIMINAL JUSTICE SYSTEM}

\section{Abstract}

The following document reviews the figures of incidental issue of redress and the civil claim as compensatory mechanisms for the victims in the criminal procedure enacted either by Act 906 of 2004 or Act 600 of 2000, which is still in force. Moreover, this paper studies the differences and similarities of both concepts.

Keywords:

Damage, Criminal Procedure, Redress, Criminal Liability, Victims. 


\section{INTRODUCCIÓN}

Cuando se encuentra frente a la comisión de una conducta punible, se advierte la presencia de varios sujetos que, directa o indirectamente, son objeto de consecuencias dentro del ilícito. El autor o partícipe del delito será quien lleve sobre sus espaldas la pena como consecuencia jurídica de su actuar; mientras que, por su parte, la víctima será aquella sobre la cual recae un daño producido por la ejecución del delito.

Teniendo en cuenta lo mencionado, es apropiado resaltar que en un sistema penal como el vigente no sólo se debe plantear la pena para el sujeto activo dentro del hecho reprochable, sino que se debe resarcir a la víctima examinando y consiguiendo su reparación integral, de tal forma que se satisfagan las necesidades que nacieron con la comisión de la conducta antijurídica y culpable.

Por ello, la víctima ha tomado protagonismo en los últimos años dentro del proceso penal. En nuestra normativa vigente, esta figura encuentra consagración y amparo a lo largo de la doctrina, la jurisprudencia y el ordenamiento positivo.

De cara a una viable solución del conflicto armado en Colombia, cabe preguntarse ¿qué pasará con las víctimas en Colombia?, por lo cual, el texto a desarrollar busca solventar dudas frente al rol de la víctima en el proceso penal.

El presente escrito se encuentra dividido en tres apartes. En un primer momento se expondrá el tema de las víctimas en Colombia, dónde se encuentra su protección y bajo el amparo de qué normas están; en segundo término, se pasará a explicar las figuras de la demanda de parte civil y del incidente de reparación integral (tomando como base las semejanzas y diferencias de las mismas, enunciando brevemente su procedimiento y haciendo un análisis a partir de la norma escrita y del ordenamiento que las rigen); por último, se establecen unas breves conclusiones, teniendo en cuenta las similitudes y divergencias encontradas en las figuras en cuestión. 


\section{La víctima según las leyes colombianas vigentes}

En la Constitución Política de Colombia de 1991 se encuentra amparada la figura de las víctimas. Allí se encuentra el artículo 250 numeral 6 que refiere como un deber de la Fiscalía General de la Nación brindar asistencia a las víctimas y "disponer el restablecimiento del derecho y la reparación integral de los afectados con el delito", de donde se colige una definición amplia según la cual víctima es toda persona afectada con el delito. (Sala de Casación Penal. Proceso No. 34993 de 2010).

Por su parte, en la Ley 906 de 2004 - Código de Procedimiento Penal vigente - se encuentra expresamente el artículo 132 que contiene:

Art. 132. Víctimas. Se entiende por víctimas, para efectos de este código, las personas naturales o jurídicas y demás sujetos de derechos que individual o colectivamente hayan sufrido algún daño (directo) como consecuencia del injusto. ${ }^{1}$

En tanto al desarrollo jurisprudencial, la Corte Constitucional las entiende así:

[...] son titulares de los derechos a la justicia, la verdad y la reparación las víctimas y perjudicados con el delito que hubiesen sufrido un daño real, concreto y específico, cualquiera que sea la naturaleza de éste. (Sentencias: C - 516 de 2007; C-370 de 2006; C-228 de 2002; C-578 de 2002).

Desarrollando lo expresado, el mismo tribunal señala:

Para acreditar la condición de víctima se requiere que haya un daño real, concreto y específico cualquiera que sea la naturaleza de éste, que legitime la participación de la víctima o de los perjudicados en el proceso penal para buscar la verdad y la justicia, el cual ha de ser apreciado por las autoridades judiciales en cada caso. Demostrada la calidad de víctima, o en general que la persona ha sufrido un daño real, concreto y específico, cualquiera sea la naturaleza de éste, está legitimada para constituirse en parte civil, y puede orientar su pretensión a obtener exclusivamente la realización de la justicia, y la búsqueda de la verdad, dejando de lado cualquier objetivo patrimonial. (Sentencia C-516 de 2007).

\footnotetext{
${ }^{1}$ La expresión directo, colocada entre paréntesis, fue declarada inexequible por la Corte Constitucional en la sentencia C-516 del 11 de julio de 2007.
} 
En cuanto al ámbito internacional se expresa que:

Se entenderá por víctima a toda persona que haya sufrido daños individual o colectivamente, incluidas lesiones físicas o mentales, sufrimiento emocional, pérdidas económicas o menoscabo sustancial de sus derechos fundamentales, como consecuencia de acciones u omisiones que constituyan una violación manifiesta de las normas internacionales de derechos humanos o una violación grave del derecho internacional humanitario. Cuando corresponda, y en conformidad con el derecho interno, el término 'víctima' también comprenderá a la familia inmediata o a las personas a cargo de la víctima directa y a las personas que hayan sufrido daños al intervenir para prestar asistencia a las víctimas en peligro o para impedir la victimización. (ONU, 2005).

Por último, y no menos importante, debe señalarse que la Corte Suprema de Justicia ha reiterado en sus providencias que:

Según el artículo 132 de la Ley 906 de 2004, víctima es toda persona natural o jurídica que individual o colectivamente ha sufrido algún perjuicio como consecuencia del injusto, calidad que le otorga el derecho de acceder a la actuación e impone reconocerla como tal en el proceso.

Sin embargo, los derechos a la verdad, la justicia y la reparación que habilitan tal intervención no son absolutos en cuanto se requiere la acreditación de un daño concreto, baremo que también se traslada al campo del ejercicio impugnatorio al ser necesario que quien promueva los recursos, además de tener legitimación en el proceso, dado el reconocimiento como interviniente o parte, tenga legitimación en la causa a través del interés jurídico para atacar la decisión si le ha irrogado algún perjuicio. (Providencias de 2009, Rad. 32564; 2008, Rad. 28788 y Rad. 26703; 2007, Rad. 26077; 2006, Rad. 22289).

\section{Los derechos de las víctimas: la reparación y las formas de llegar a ella}

Teniendo claro lo anterior, se debe en este instante señalar cuáles son los derechos de las víctimas en un sistema garantista como el que ampara el legislador en Colombia. Es de cotidiano reconocimiento que no basta con "causarle un daño al agresor" como método de retribución "Hammurabiana" para resarcir los perjuicios ocasionados. Muy por el contrario, existen otros derechos que quizás son más importantes en nuestra sociedad. 
Hoy por hoy los derechos de las víctimas de un delito son la verdad, la justicia y la reparación integral. Estos son derechos que se encuentran protegidos en el sistema penal con tendencia acusatoria instaurado mediante Acto Legislativo 03 de 2002 y desarrollado por la Ley 906 de 2004, luego modificado por la Ley 1395 de 2010, entre otras. Esta protección no implica un traslado automático de todas las formas y esquemas de intervención en los que la víctima ejerció sus derechos, ya que en el anterior sistema procesal penal (regulado por la Ley 600 de 2000) ya se contemplaban mecanismos para reparar a la víctima. (Gaviria, 2008).

El ejercicio de los derechos anteriormente mencionados deberá hacerse de manera compatible con los rasgos estructurales y las características esenciales del nuevo sistema procesal penal al que se ha hecho mención, así como la recordación constante de las definiciones que el propio constituyente adoptó al respecto; para lo cual, sería propio expresar la caracterización de las víctimas como intervinientes especiales a lo largo del proceso penal no supeditadas al fiscal, sino en los términos que autónomamente fije el legislador.

En este punto, es preciso recalcar que la reparación de daños dentro del proceso penal, ya ha tenido una larga trayectoria, tanto en la jurisprudencia como en la norma; ello, con el objetivo de imponer la obligación de restituir e indemnizar a la víctima en el marco del proceso penal como medio válido para concretar y conseguir la reparación de daños y perjuicios ocasionados con el delito. (Sala de Casación Penal. Sentencia de 1982)

Ahora bien, con respecto a las figuras que se pretenden estudiar en este escrito, es necesario entender la diferencia que existe entre una demanda civil - vista como el ejercicio del derecho de acción - y la naturaleza propia de un incidente, ya que la acción doctrinariamente ha sido entendida como el "derecho público subjetivo que tiene todo sujeto de derecho, de acudir a los órganos jurisdiccionales para reclamarles la satisfacción de una pretensión mediante un proceso" (López, 2012); por otra parte, el incidente podríamos definirlo como un trámite de audiencias, con características de procedimiento civil pero trámite de juicio penal, por medio del cual se plantea resarcir de manera íntegra los daños causados por la comisión del delito y que no se hayan satisfecho con 
anterioridad, teniendo en cuenta la necesidad de demostrar el vínculo existente entre el daño, el ya declarado responsable penal y la víctima que debe acreditarse durante el trámite. Del incidente debe mencionarse que rompe "o con el paradigma de la justicia retributiva, la Ley 906 de 2004 acogió como se dijo en precedencia los postulados de la justicia restaurativa, como fórmula efectiva y positiva para la solución de conflictos derivados del delito, la víctima dentro de este esquema interviene en el proceso penal”. (Avellaneda \& Arguello, 2013).

En la Ley 600 del 2000: “(...) la reparación del daño ocasionado por el delito tiene como finalidad, como lo ha señalado la Corte Constitucional, dejar a la víctima y a los perjudicados por el hecho punible en la situación más próxima a la que existía antes de la ocurrencia del mismo”. (Sentencia C-916 de 2002).

En ese orden de ideas, con respecto a la Ley 600 de 2000, la indemnización de perjuicios se reguló dentro del proceso penal, basado en lo siguiente:

i. La reparación de la conducta punible incluye los daños materiales y morales y se refiere tanto a daños individuales como colectivos.

ii. La liquidación de los perjuicios ocasionados por el delito debe hacerse de acuerdo con lo acreditado en el proceso penal. (Artículo 42 de la ley 600 de 2000).

iii. La indemnización integral de los perjuicios ocasionados para ciertos delitos trae como consecuencia la extinción de la acción penal.

iv. La regulación de medidas para garantizar la indemnización integral, de tal manera que el juez penal podrá no solo disponer en la sentencia condenatoria el remate de bienes decomisados, sino en el curso del proceso adoptar medidas sobre bienes del procesado. ${ }^{2}$

v. La determinación de los obligados, de tal forma que el juez penal podrá llamar a quienes, según la ley sustancial, estén obligados a responder solidariamente. (Artículo 46 de la ley 600 de 2000).

${ }^{2}$ Así, en el artículo 50 de la Ley 600 de 2000, se postula la admisión de la demanda y facultades de la parte civil. 
vi. Cuando no es posible la determinación objetiva de los perjuicios, se acude a los criterios que establece el Código Penal. (Artículo 56 de la ley 600 de 2000).

vii. La solicitud de la reparación ante la jurisdicción civil, excluye la posibilidad de acudir a la jurisdicción penal para reclamar la reparación de los perjuicios.(Artículo 52 de la ley 600 de 2000).

viii. La obtención del beneficio de suspensión condicional de la ejecución de la pena, puede ser supeditada a que se efectúe la reparación integral de los perjuicios.

ix. En la sentencia condenatoria debe incluirse la condena en perjuicios cuya existencia haya sido demostrada en juicio, a menos que exista prueba de que se promovió de manera independiente la acción civil de indemnización. (Navarro, 2009)

Por otra parte, con el proceso acusatorio se amplía el espectro y alcance de la reparación desde el punto de vista de los derechos de las víctimas, que a diferencia del estatuto penal anterior, se centraba únicamente en la indemnización material y moral. Con la Ley 906 del 2004 se le dan más atribuciones y derechos a la víctima. Por eso, la reparación se muestra como una hipótesis de justicia restaurativa, donde: " $E l$ Estado tiene (...) un interés en que el daño sea resarcido del modo más rápido posible”. (Navarro, 2009)

Se abre campo, de igual manera, a brindarle a la víctima un conjunto de beneficios durante el trámite del incidente de reparación, tales como el postulado en el artículo 136 de la Ley 906/04, que habla sobre el derecho a recibir información.(Navarro, 2009).

Así, la Ley 906/04 postula a tres partes como titulares, los cuales podrán interponer el incidente de reparación integral en un término de 30 días desde el anuncio del fallo de responsabilidad penal; estas partes son: víctima, fiscalía y ministerio público. (Navarro, 2009). Lo anterior se ha modificado, ya que no necesitamos tan solo el anuncio del fallo de responsabilidad como menciona el autor Navarro, sino que, en la actualidad, requerimos sentencia condenatoria; hay que tener en cuenta que el libro del abogado es anterior a la modificación a la que se hace mención. 
De igual forma, es fundamental entender el cambio jurisprudencial que tuvo lugar en vigencia de la Ley 600 del 2000, dado que la Corte Constitucional, en Sentencia C-1149 del 2001, consideraba que la naturaleza de la acción civil dentro del proceso penal era netamente indemnizatoria, y su única y exclusiva finalidad sería el restablecimiento del derecho y el resarcimiento de todos los daños ocasionados como consecuencia de la comisión de un acto delictivo; lo anterior daba lugar a que no se tuvieran en cuenta otro tipo de daños.

En el año 2002, la Corte Constitucional cambio su línea jurisprudencial respecto a este tema, estableciendo en la sentencia C-228 que los derechos de las víctimas y de los perjudicados por un delito no se encontraban circunscritos a la reparación material sin que se orientara a su restablecimiento integral.

Es preciso mencionar que la posición de la víctima frente al proceso en cada uno de los sistemas es completamente diferente, ya que en los términos de la Ley 600 de 2000, la vinculación del tercero civilmente responsable podía solicitarse desde la admisión de la demanda de parte civil, o incluso antes de proferirse la providencia de cierre de la investigación, reconociéndosele, de conformidad con el artículo 141 de la citada Ley, los mismos derechos y facultades de cualquier sujeto procesal.

\section{Como menciona el Supremo Constitucional:}

Mediante el Acto Legislativo 03 de 2002 y la Ley 906/04 se avanzó hacia un sistema de investigación y juzgamiento penal de marcada tendencia acusatoria, que introduce un nuevo enfoque respecto de los actores que integran la relación jurídico-procesal, previendo expresamente la intervención en el proceso de: (i) las víctimas; (ii) el imputado; (iii) el fiscal; (iv) el juez de conocimiento; (v) el Ministerio Público; (vi) el juez de control de garantías. Tales modificaciones incidieron en la regulación legal del tema bajo examen: al (i) desaparecer la parte civil; (ii) al dejar el tercero civilmente responsable de ser sujeto procesal; (iii) al permitirse durante la etapa de investigación la imposición de una medida cautelar consistente en la entrega provisional del vehículo, nave o aeronave, para el caso de los delitos culposos; y (iv) al establecer un incidente de reparación integral, el cual se lleva a cabo con posteridad al fallo condenatorio y previa solicitud expresa de la víctima, del fiscal o del Ministerio Público, durante el cual es citado quien debe responder por el hecho ajeno.(Sentencia C-250 de 2011). 
De lo anterior, se puede mencionar que existe un gran número de diferencias entre el incidente de reparación integral y la demanda de parte civil.

En cuanto a su procedencia y ejercicio se tiene que:

- En la Ley 906 de 2004, una vez emitido el fallo de culpabilidad puede tener lugar el incidente de reparación integral, el que tiene por objeto la reparación de los daños causados a la víctima con la conducta criminal. Se enmarca en los derechos esenciales de la misma a obtener justicia, verdad y reparación, por lo cual tiene arraigo constitucional y su desarrollo legal está en los artículos 102 y siguientes de la Ley 906 de 2004.

- Están legitimados para presentar la pretensión de reparación integral la víctima, sus herederos, sucesores o causahabientes cuando la reparación tiene exclusivamente carácter económico. Si es de otra naturaleza, podrán hacerlo el fiscal o el ministerio público por solicitud de la víctima.

- Por el contrario, en la Ley 600 de 2000, la demanda de parte civil podría presentarse ante la jurisdicción civil o penal y se podía intentar la constitución como parte civil en cualquier momento, a partir de la resolución de apertura de instrucción mediante la presentación de la demanda de parte civil o incluso antes de proferirse la providencia de cierre de la investigación.

Por otra parte, en cuanto al trámite de cada uno de los procedimientos de reparación de victima en cada uno de los sistemas tenemos grandes diferencias, bajo el sistema penal acusatorio, en la primera audiencia de trámite, el incidentante formula su pretensión oralmente e indica las pruebas que hará valer. El juez examina la admisibilidad de la pretensión y tiene dos opciones para resolver: (i) la rechaza por falta de legitimación, o por pago efectivo de los perjuicios, si la pretensión fuere solamente económica; o (ii) la admite. Aceptada la pretensión, el juez la pone en conocimiento del declarado penalmente responsable y ofrece a las partes la posibilidad de conciliación que, de prosperar, pone fin al incidente. (Bernate, 2005). 
En caso contrario, el juez convoca a los intervinientes a una nueva audiencia dentro de los ocho días siguientes para intentarla una vez más, con la advertencia al culpable, que en esta nueva oportunidad debe ofrecer sus medios de prueba con los que se proponga oponerse a las pretensiones de la víctima, caso en el cual, dispone la práctica de las pruebas ofrecidas por cada parte y después de escuchar el argumento de sus pretensiones, adopta la decisión que pone fin al incidente, la cual debe ser incorporada a la sentencia.

La inasistencia injustificada del solicitante a cualquiera de las audiencias (primera de trámite, de pruebas o alegaciones) se entiende como desistimiento de la pretensión y genera el archivo de la solicitud y la respectiva condena en costas. Si no comparece injustificadamente el declarado penalmente responsable, el juez dispone la práctica de la prueba ofrecida por el incidentante y, con base en ella, adopta la decisión que corresponda. En cualquier caso quien no comparece queda vinculado a los resultados de la decisión. ${ }^{3}$

Por su parte, en el modelo de la Ley 600 de 2000, el esquema de parte civil es completamente diferente; el trámite establecido es el siguiente:

Dentro de los tres (3) días siguientes a aquél en que se presente el escrito de demanda, el funcionario judicial que conoce del proceso decidirá mediante providencia interlocutoria sobre su admisión o rechazo. La providencia que resuelve sobre la demanda de parte civil es apelable en el efecto devolutivo. Admitida la demanda de parte civil, ésta quedará facultada para solicitar la práctica de pruebas orientadas a demostrar la existencia de la conducta investigada, la identidad de los autores o partícipes, su responsabilidad y la naturaleza y cuantía de los perjuicios ocasionados. Podrá igualmente denunciar bienes del procesado y solicitar su embargo y secuestro, y asimismo, interponer recursos contra las providencias que resuelvan sobre las materias. La demanda será rechazada cuando esté acreditado que se ha promovido independientemente la acción civil por el mismo demandante, que se ha hecho efectivo el pago de los perjuicios, que se ha producido la reparación del daño o que quien la promueve no sea el perjudicado directo.

${ }^{3}$ Todo esto a partir de la lectura del articulado referente al tema en cuestión. 
También procede el rechazo cuando la demanda se dirija contra el tercero civilmente responsable y la acción civil se encuentre prescrita. En cualquier momento del proceso en el que se acredite cualquiera de las situaciones descritas, mediante providencia interlocutoria, se dará por terminada la actuación civil dentro del proceso penal. La acción civil, dentro del proceso penal, se adelantará en cuaderno separado en el que se allegarán todas las pruebas y actuaciones relacionadas con la pretensión patrimonial.

Por último, es importante tener en cuenta que:

Los artículos 86 y 89 de la Ley 1395 de 2010, modificatorios de los artículos 102 y 106 de la Ley 906 de 2004, prevén la procedencia y ejercicio del incidente de reparación integral una vez en firme la sentencia condenatoria, y precisa el término de caducidad para la solicitud de reparación integral a los treinta (30) días después de haber quedado en firme el fallo condenatorio.

Circunstancias que, para la Corte, no vulneran los derechos del tercero civilmente responsable, ya que dichas disposiciones no entrañan limitación a los derechos de participación en las decisiones del tercero civilmente responsable, puesto que el derecho a su participación dentro del proceso penal será constitucionalmente legítima únicamente a partir del momento en que se ha determinado la responsabilidad penal del sujeto por el cual deberá responder civilmente, momento que surge necesariamente - después de encontrarse en firme la sentencia de condena - con la iniciación del incidente de reparación integral y su citación al mismo, en el que contará con todos los derechos y garantías tendientes a su participación activa y a la construcción de la decisión que lleve a su culminación. Asimismo, al ser citado el tercero civilmente responsable al incidente de reparación integral, cuenta con todas las garantías de acceso a la justicia, con la posibilidad de debatir, dentro del incidente, la existencia o no del perjuicio y el monto de la reparación; a objetar las pretensiones de la víctima, así como su relación para con el condenado y su deber de reparación; a solicitar la citación al asegurador; a participar en las audiencias; a conciliar y a interponer los recursos a que haya lugar, en desarrollo de los postulados establecidos en los artículos 102 y ss. del CPP. En cuanto a la caducidad de la solicitud de reparación integral treinta (30) días después de haber quedado en firme la sentencia de 
condena, tampoco se vulnera el derecho del tercero civilmente responsable a la participación en las decisiones que le afectan y a la tutela judicial efectiva, ya que si bien, en desarrollo de la libertad de configuración legislativa el legislador estableció dicho término con el fin de racionalizar los procedimientos judiciales e imprimirles seguridad jurídica, el límite se considera válido pues establecida la constitucionalidad del papel del tercero civilmente responsable circunscrito a la etapa del incidente de reparación integral, la norma acusada busca la celeridad en los procesos judiciales, sin menoscabo de los derechos de partes e intervinientes. (Sentencia C-250 de 2011).

En concordancia con lo mencionado a lo largo de este escrito, y a partir de una comparación de lo tipificado en ambas legislaciones, es preciso anotar que lo contemplado en la Ley 600 de 2000 y en la Ley 906 de 2004 , en cuanto a la reparación de víctimas, tiene ciertas semejanzas pero grandes diferencias.

En cuanto a las similitudes, se pone en evidencia:

- Tanto la demanda de parte civil como el incidente de reparación integral encuentran su fundamento en el Código Penal, artículo 94, que establece la obligación que nace de toda conducta punible para reparar los daños materiales y morales causados con ocasión de la conducta.

- El mismo Código Penal estableció que son titulares de la acción civil las personas naturales, sus sucesores y también las personas jurídicas perjudicadas directamente por la conducta punible.

- La obligación de indemnizar se encuentra en cabeza de los penalmente responsables en forma solidaria, sumándose otros terceros que puedan llegar a estar obligados a responder.

- La tasación de la indemnización de perjuicios, en cualquiera de los dos procedimientos, podrá ascender hasta a 1000 SMLMV, teniendo en cuenta la naturaleza de la conducta y la magnitud del daño causado.

- Ambas acciones son de carácter rogado, es decir, se requiere el interés de los perjudicados para iniciar la demanda de acción civil y la acción de reparación integral. 
- En ambos eventos hay lugar al rechazo de las pretensiones. En la acción civil, la demanda puede ser rechazada en caso de que la acción civil se haya promovido de forma independiente al proceso penal, o si se demuestra la reparación del daño o la falta de interés al no ser el perjudicado directo. En el incidente de reparación integral se rechaza por las mismas causas cuando se demuestre que no es víctima quien la promueve o que se ha acreditado el pago de los perjuicios.

- Es posible que las personas perjudicadas se constituyan en parte civil de forma separada o conjunta, lo mismo ocurre en el incidente de reparación integral en donde las víctimas podrían presentar sus pretensiones en forma conjunta, como en el caso de sucesores que acumulen sus pretensiones teniendo en cuenta que comparten la misma calidad.

- Si bien el trámite es distinto en ambos casos, es posible vincular a los terceros civilmente responsables al proceso.

En contraste, las divergencias conceptuales, técnicas y de fondo que se encuentran entre las dos instituciones sujetas a estudio son:

Con respecto a la demanda de parte civil:

- Para poder restablecer el derecho y resarcir el daño es necesario que el perjudicado y sus sucesores se constituyan como parte civil dentro de la actuación penal, siempre a través de abogado. Es decir, es necesaria la solicitud rogada de la víctima pero mediante representación.

- La acción civil puede ejercerse dentro de la jurisdicción civil o también dentro del mismo proceso penal a elección de los interesados. Esta constitución como parte civil puede intentarse en cualquier momento dentro del proceso penal o paralelo al mismo en la jurisdicción civil; lo que implica que no necesariamente debe haber una sentencia condenatoria en firme.

- El trámite de constitución de la parte civil comienza con la presentación de la demanda de constitución que establezca los lineamientos generales de la indemnización, como la identificación del 
perjudicado, de los presuntos responsables, los hechos generadores de los daños y perjuicios y los mismos de orden material y moral estimando la cuantía y las medidas para el resarcimiento.

- Las pruebas que se pretendan hacer valer deberán ser presentadas junto con la demanda de la parte civil.

- Las formas de notificación de admisión de la demanda de la parte civil incluyen la notificación personal al demandado así como el emplazamiento en caso de que no se pueda surtir la notificación personal. En este caso no hay lugar a la conciliación para poner fin a la acción civil.

- La demanda se admite o rechaza dentro de los tres (3) días siguientes a la presentación de la misma, decisión mediante auto interlocutorio que se puede apelar en el efecto suspensivo.

- Una vez admitida la demanda se deberá solicitar la práctica de pruebas para demostrar los perjuicios y su naturaleza, así mismo, habría lugar a solicitar embargo y secuestro de bienes del procesado.

- Si bien la demanda de la parte civil se maneja en cuaderno aparte paralelo al proceso penal, la decisión definitiva respecto de la misma tiene lugar dentro de la sentencia condenatoria que se profiere al final del proceso penal.

- Es posible vincular a un tercero civilmente responsable en la misma demanda de constitución de parte civil, o de forma posterior a ésta, mediante escrito separado que cumpla con los requisitos de la demanda de la parte civil.

De manera correlativa, en el incidente de reparación:

- Se requiere previa solicitud expresa de la víctima, del Fiscal o del Ministerio Público en representación de la misma. En este caso, la víctima lo puede llevar a cabo directamente y no requiere representación a través de abogado.

- El incidente de reparación integral se resuelve en audiencia pública que será convocada por el juez fallador dentro de los ocho (8) días siguientes a la solicitud presentada. 
- La sentencia condenatoria debe necesariamente estar en firme al momento de solicitar la reparación integral, lo cual implica que no haya lugar a recursos en contra del fallo definitivo (con anterioridad sólo se requería el sentido del fallo y que éste declarara la responsabilidad penal del acusado).

- El trámite del incidente de reparación integral se llevará a cabo mediante audiencia en donde la pretensión será formulada verbalmente, incluyendo la forma de reparación integral a la que se aspira y la indicación de las pruebas a hacer valer.

- En este caso no se trata de la persona demandada, sino de la persona condenada como penalmente responsable de la conducta punible, quien deberá entrar a responder por los perjuicios causados.

- Una vez se admite la pretensión se pone en conocimiento del condenado y se ofrece la posibilidad de las partes de una conciliación que podrá poner fin al incidente. En caso de que no haya conciliación se citará a una nueva audiencia dentro de los ocho (8) días siguientes para intentar la conciliación nuevamente.

- En caso de no lograrse la conciliación en la segunda audiencia se procede con el ofrecimiento de los medios de prueba del sentenciado. En esta audiencia se llevará a cabo entonces la práctica de la prueba y habrá lugar a que ambas partes hagan las correspondientes alegaciones.

- La decisión de la reparación integral se tomará en la misma audiencia mediante sentencia, lo que es diferente en el caso de la Ley 600 teniendo en cuenta que en ese caso no ha habido sentencia de condena, y por ende, la acción civil se decide en conjunto con la condena.

- En este caso hay, además, caducidad de la acción, teniendo en cuenta que la solicitud de reparación se deberá presentar dentro de los treinta (30) días siguientes de que quede en firme el fallo condenatorio.

- También es posible vincular al tercero civilmente responsable, pero no mediante la demanda de la parte civil, sino que éste po- 
drá ser citado al incidente a solicitud de la víctima o el defensor del condenado dentro de la audiencia que abra trámite al incidente. Frente a lo anterior, la Corte Constitucional ha dicho que el tercero civilmente responsable también tiene garantías frente al derecho de defensa en relación con el decreto y la práctica de medidas cautelares en su contra, en caso de que la vinculación que haga con anterioridad a la audiencia de incidente de reparación.

- En el incidente hay mención expresa respecto a la viabilidad de citar al asegurador, quien deberá participar dentro del curso del incidente, y en caso tal, demostrar la inexistencia de obligación de indemnizar a las víctimas.

\section{CONCLUSIONES}

- El Derecho Penal del siglo XXI no se completa con el simple "castigo" que se le debe aplicar a quien comete un delito.

- Las víctimas han tomado especial importancia dentro de un proceso penal, reconociéndoles sus derechos a la verdad, la justicia y la reparación.

- La legislación colombiana siempre se ha encontrado acompasada con los derechos de las víctimas, por ello ha contemplado figuras como la demanda de parte civil y el incidente de reparación integral para conseguir que la víctima sea resarcida en el daño que se le haya ocasionado.

- Estas figuras, de legislaciones distintas y procedimientos penales disímiles, tienen un primigenio fin similar, y es resarcir el daño causado a la víctima.

- Tienen diferencias de fondo, ya que los trámites son distintos, además de que en la Ley 600 el trámite era paralelo al proceso penal, mientras que el la Ley 906 el incidente comienza sólo a partir de la condena del acusado.

- Con el incidente de reparación integral se ha trascendido más allá del simple resarcimiento económico y se han logrado otros mecanismos de reparación al ofendido. 


\section{REFERENCIAS}

Avellaneda, L. \& Arguello, L. (2013). La víctima y el trámite de incidente de reparación integral en el nuevo sistema penal acusatorio como presupuesto de aproximación a la justicia restaurativa. Verba Iuris 1. Recuperado de: http://www.unilibre.edu.co/verbaiuris/images/stories/vol1/dpr2. pdf

Bernate, F. (2005). Sistema Penal Acusatorio. Bogotá: Editorial Universidad del Rosario.

Gaviria, V. (2008). Víctimas, acción civil y sistema acusatorio. 2 Ed. Bogotá: Editorial Universidad Externado de Colombia.

López, H. (2012). Instituciones de Derecho Procesal Civil Colombiano parte general. $4^{\mathrm{a}} \mathrm{Ed}$. Bogotá: Editorial Dupre

Navarro, A. (2009). La justicia restaurativa y el incidente de reparación. Bogotá D.C.: Leyer.

Organización de las Naciones Unidas. Comisión de Derechos Humanos. Resolución 2005/35. Abril 19 de 2005. Principios y Directrices Básicos sobre el Derecho de las Víctimas de Violaciones Graves de los Derechos Humanos y las Libertades. Recuperado de: http://ap.ohchr.org/documents/F/CHR/ resolutions/E-CN_4-RES-2005-35.doc

República de Colombia. Congreso de la República. Ley 600. (Julio 24 de 2000). Por la cual se adoptan medidas en materia de descongestión judicial. Diario Oficial 47.768 , Bogotá, D. C.: Imprenta Nacional de Colombia.

República de Colombia. Congreso de la República. Ley 906 (Agosto 31 de 2004). Por la cual se expide el Código de Procedimiento Penal. Diario Oficial 45.658, Bogotá, D. C.: Imprenta Nacional de Colombia.

República de Colombia. Congreso de la República. Ley 1395 (Julio 12 de 2010). Por la cual se expide el Código de Procedimiento Penal. Diario Oficial 45.658, Bogotá, D. C.: Imprenta Nacional de Colombia.

República de Colombia. Consejo Superior de la Judicatura (2010). Constitución Política de Colombia de 1991. Bogotá: Imprenta Nacional de Colombia.

República de Colombia. Corte Constitucional. Sentencia C-228. Abril 3 de 2002. Magistrados Ponentes: Dr. Manuel José Cepeda y Dr. Eduardo Montealegre Lynnet. 
República de Colombia. Corte Constitucional. Sentencia C-250. Abril 6 de 2011. Magistrado Ponente: Dr. Mauricio González Cuervo.

República de Colombia. Corte Constitucional. Sentencia C-370. Mayo 18 de 2006. Magistrados ponentes: Dr. Manuel José Cepeda, Dr. Jaime Córdoba Triviño, Dr. Rodrigo Escobar Gil, Dr. Marco Gerardo Monroy Cabra, Dr. Álvaro Tafur Galvis y Dra. Clara Inés Vargas.

República de Colombia. Corte Constitucional. Sentencia C-516. Julio 11 de 2007. Magistrado Ponente: Dr. Jaime Córdoba Triviño.

República de Colombia. Corte Constitucional. Sentencia C-578. Junio 30 de 2002. Magistrado ponente: Dr. Manuel José Cepeda.

República de Colombia. Corte Constitucional. Sentencia C-916. Octubre 29 de 2002. Magistrado Ponente: Dr. Manuel José Cepeda.

República de Colombia. Corte Constitucional. Sentencia C-1149. Octubre 31 de 2001. Magistrados Ponentes: Dr. Rodrigo Escobar Gil, Dr. Marco Gerardo Monroy Cabra y Dr. Alvaro Tafur Galvis.

República de Colombia. Corte Suprema de Justicia. Sala de Casación Penal. Providencia del 11 de noviembre de 2009. Radicado 32564. Recuperado de: http://www.usergioarboleda.edu.co/derecho_penal/indice_tematico_ sistema_penal_acusatorio/32564(11-11-09).doc

República de Colombia. Corte Suprema de Justicia. Sala de Casación Penal. Providencia del 6 de marzo de 2008. Radicado 28788. Recuperado de: http://www.usergioarboleda.edu.co/derecho_penal/indice_tematico_sistema_penal_acusatorio/28788(06-03-08).doc

República de Colombia. Corte Suprema de Justicia. Sala de Casación Penal. Providencia del 6 de marzo de 2008. Radicado 26703. Recuperado de: http://www.usergioarboleda.edu.co/derecho_penal/indice_tematico_sistema_penal_acusatorio/26703(06-03-08).doc

República de Colombia. Corte Suprema de Justicia. Sala de Casación Penal. Providencia del 1 de noviembre de 2007. Radicado 26077. Recuperado de: http://www.usergioarboleda.edu.co/derecho_penal/indice_tematico_sistema_penal_acusatorio/26077(01-11-07).doc

República de Colombia. Corte Suprema de Justicia. Sala de Casación Penal. Providencia del 10 de agosto de 2006. Radicado 22289. Recuperado de: http://www.usergioarboleda.edu.co/derecho_penal/indice_tematico_sistema_penal_acusatorio/26077(10-08-06).doc 
República de Colombia. Corte Suprema de Justicia. Sala de Casación Penal. Proceso No. 34993 del 24 de Noviembre de 2010. Magistrada Ponente: Dra. Maria del Rosario González de Lemos.

República de Colombia. Corte Suprema de Justicia. Sala de Casación Penal. Sentencia de 20 septiembre de 1982. Magistrado Ponente. Dr. Gustavo Gómez Velázquez 